\title{
Supporting information for \\ High Throughput Identification and Quantification of Phospholipids in Complex Mixtures
}

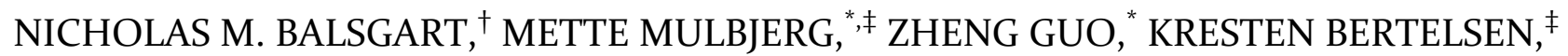 \\ THOMAS VOSEGAARD ${ }^{\dagger, a}$ \\ ${ }^{\dagger}$ Center for ultrahigh-field NMR spectroscopy, Interdisciplinary Nanoscience Center and Department of \\ Chemistry, Aarhus \\ University, Gustav Wieds Vej 14, DK-8ooo Aarhus C, Denmark. " Department of Engineering, Aarhus \\ University, Gustav Wieds Vej 10, 8000 Aarhus C, Denmark, ${ }^{\ddagger}$ DuPont Nutrition Biosciences ApS, Edwin Rahrs \\ Vej 38, DK-8220 Brabrand, Denmark. \\ aCCorresponding author: Thomas Vosegaard, tv@chem.au.dk
}

\section{P T1 relaxation of phospholipids in one phase solvent at $278 \mathrm{~K}$}

We have measured the ${ }^{31} \mathrm{P} T 1$ relaxation times for all components of a hydrolyzed soy lecithin sample. Figure S1 shows the experiment corresponding to fully relaxed spectrum with indication of the peaks for which we have measured the T1 relaxation time. Table S1 contains the measured T1 relaxation times.

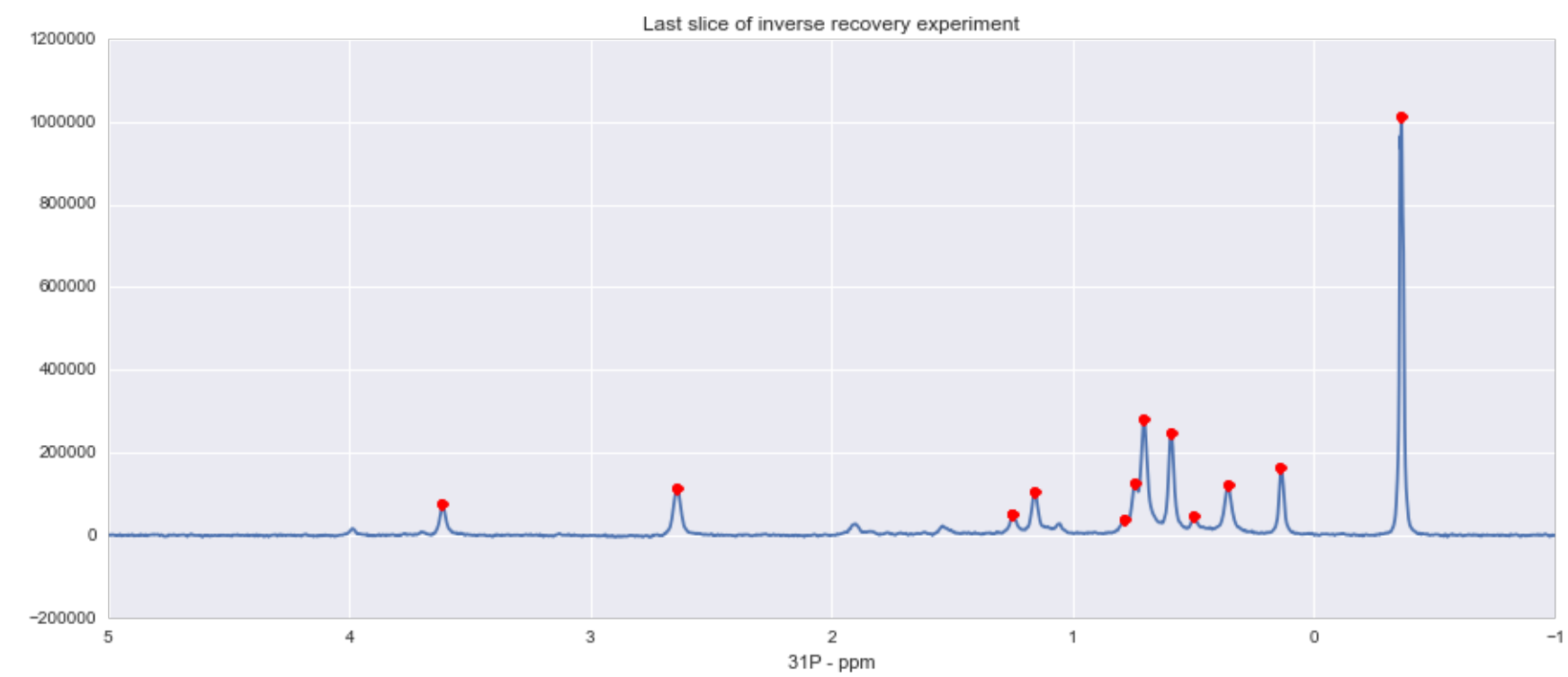

Figure S1. Fully relaxed ${ }^{31}$ P NMR spectrum of a hydrolyzed soy lecithin with indication of peaks whose T1 is determined. 
Table S1. Measured T1 relaxation times for TIBP and a number of phospholipids found in hydrolyzed soy lecithin.

\begin{tabular}{|ccrr|}
\hline ppm & I0 & alpha & T1 (s) \\
\hline $\mathbf{3 . 6 1}$ & $7.21 \mathrm{E}+04$ & 2.02 & 0.32 \\
\hline $\mathbf{2 . 6 4}$ & $1.11 \mathrm{E}+05$ & 1.95 & 0.40 \\
\hline $\mathbf{1 . 2 5}$ & $4.90 \mathrm{E}+04$ & 2.07 & 0.30 \\
\hline $\mathbf{1 . 1 6}$ & $1.02 \mathrm{E}+05$ & 2.03 & 0.33 \\
\hline $\mathbf{0 . 7 8}$ & $3.46 \mathrm{E}+04$ & 1.93 & 0.38 \\
\hline $\mathbf{0 . 7 4}$ & $1.23 \mathrm{E}+05$ & 2.01 & 0.39 \\
\hline $\mathbf{0 . 7 0}$ & $2.74 \mathrm{E}+05$ & 2.03 & 0.34 \\
\hline $\mathbf{0 . 5 9}$ & $2.43 \mathrm{E}+05$ & 2.09 & 0.40 \\
\hline $\mathbf{0 . 5 0}$ & $4.46 \mathrm{E}+04$ & 2.07 & 0.44 \\
\hline $\mathbf{0 . 3 6}$ & $1.20 \mathrm{E}+05$ & 1.99 & 0.38 \\
\hline $\mathbf{0 . 1 3}$ & $1.55 \mathrm{E}+05$ & 2.14 & 0.43 \\
\hline $\mathbf{- 0 . 3 6}$ & $9.40 \mathrm{E}+05$ & 2.26 & 1.44 \\
\hline
\end{tabular}

The relaxation values were extracted from inverse recovery experiments by fitting the intensities to the formula

$$
I=I_{0} \cdot\left(1-\alpha e^{-t / T 1}\right)
$$

We found that TIBP has by far the longest relaxation time of $T 1=1.44 \mathrm{~s}$, while the lipid components all have relaxation times in the range $0.30 \mathrm{~s} \leq T 1 \leq 0.44 \mathrm{~s}$.

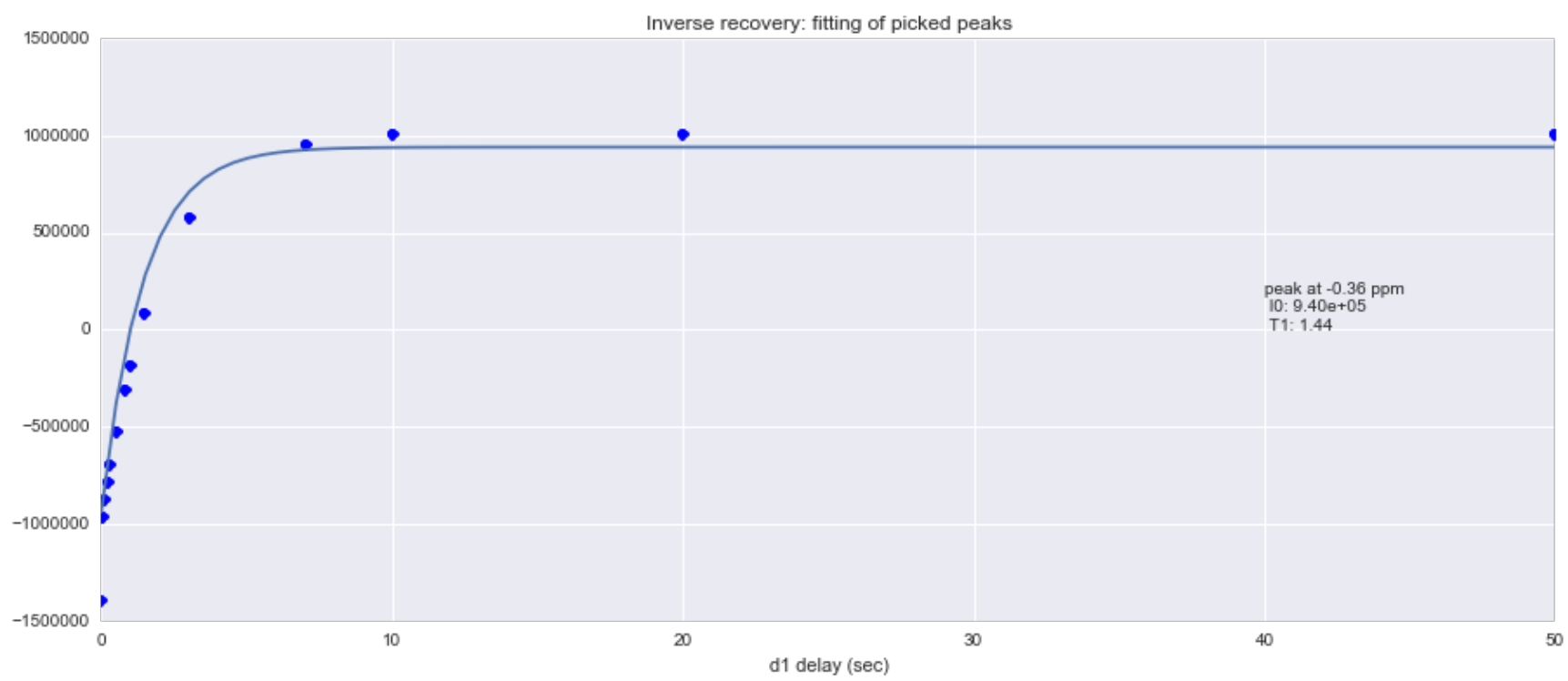

Figure S2. Inverse recovery of data for the internal standard (TIBP). d1 delay represents the inversion recovery time. 


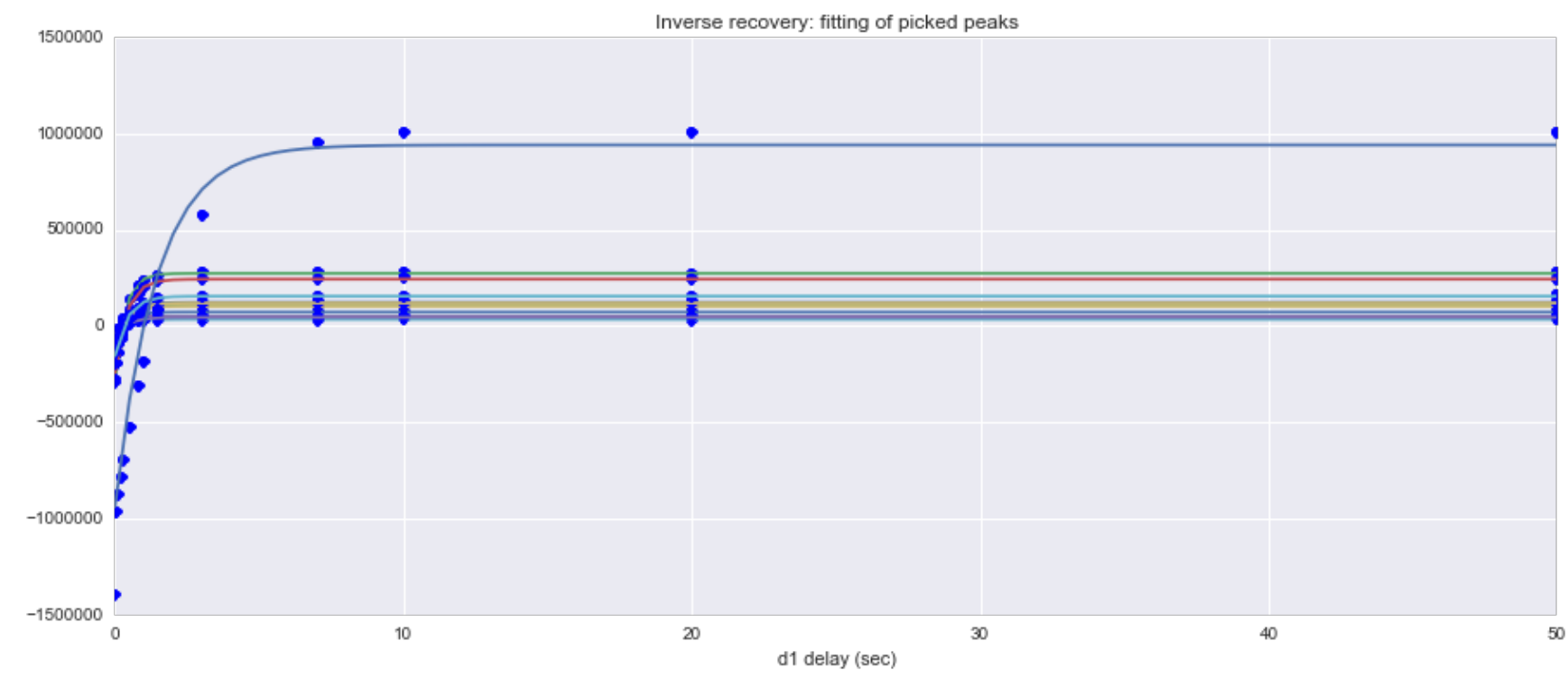

Figure S3. Inversion recovery data for all lipid ${ }^{31} \mathrm{P}$ peaks in the hydrolyzed soy lecithin sample.

Temperature and effect of increasing CDTA concentration

pH 11, Te 298K, CDTA conc. $1000 \mathrm{mM}$

pH 11, Te 278K, CDTA conc. $1000 \mathrm{mM}$
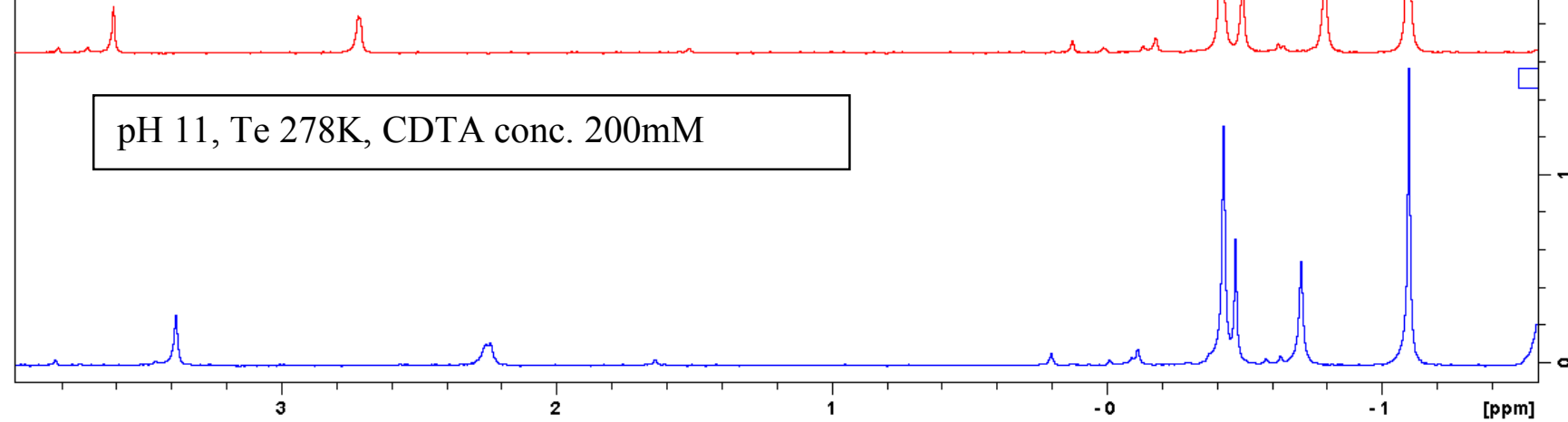

Figure S4. ${ }^{31} \mathrm{P}$ NMR experiments of the certified samples with LPA and GPC spiked in described in paper under different experimental conditions. The experimental conditions ( $\mathrm{pH}$, temperature (Te), and CsCDTA concentration) are annotated in the figure. 
Representative 2D ${ }^{1} \mathrm{H}-31 \mathrm{P}$ NMR spectra
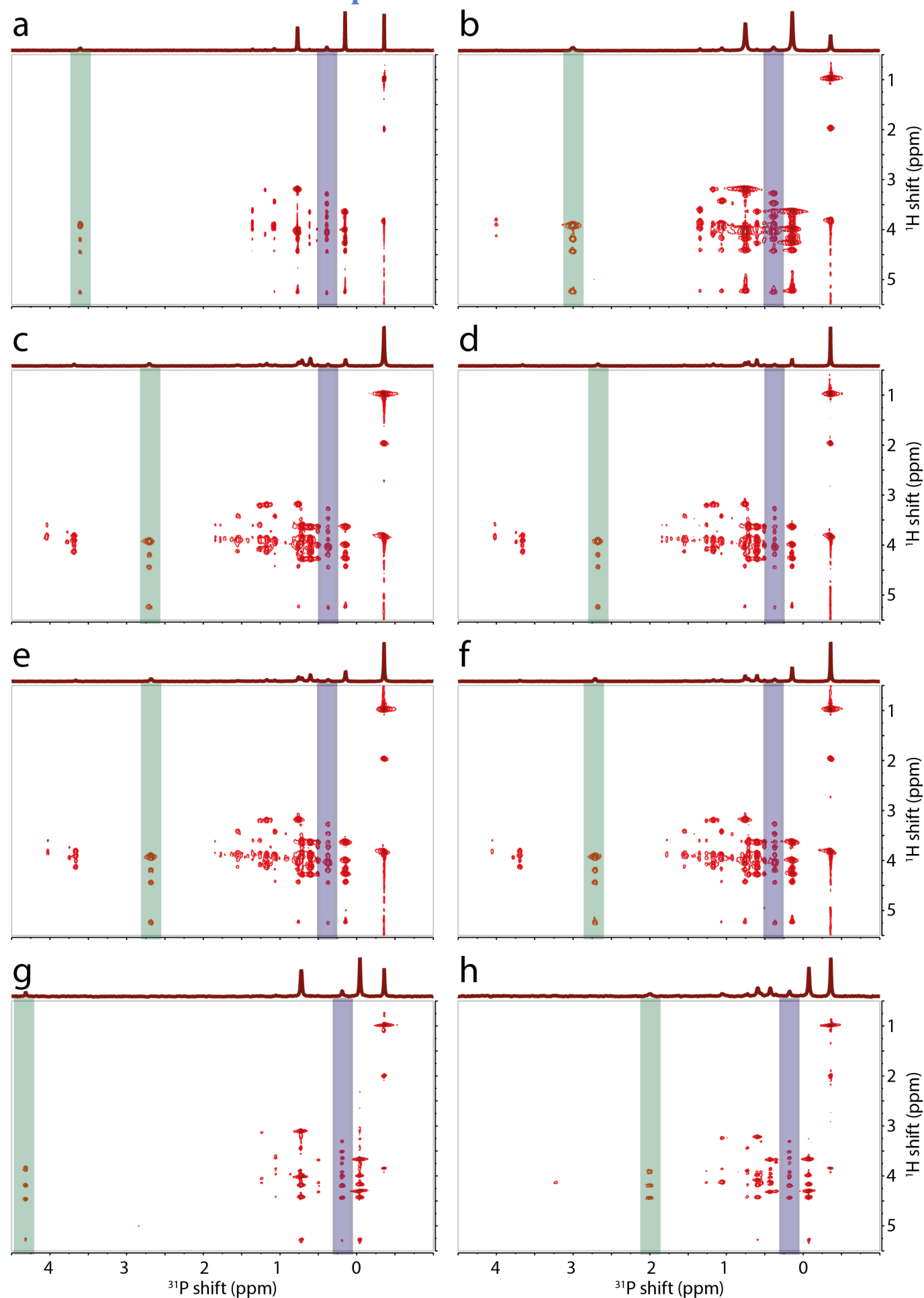

Figure S5. Typical ${ }^{1} \mathrm{H}_{-}{ }^{31} \mathrm{P}$ heteronuclear TOCSY spectra of soy lecithin samples recorded in different solvents and with different mixing times. (a,b) Certified reference sample with $38.5 \mathrm{mg}$ lipid (a) and $78.8 \mathrm{mg}$ lipid (b). (c-f) Spectra corresponding to the samples reported in Fig. 6 after hydrolysis time of 0 min (c), $30 \mathrm{~min}$ (d), $60 \mathrm{~min}$ (e), and $90 \mathrm{~min}$ (f). (g,h) Spectra of soy lechitin samples subjected to different hydrolysis times and dissolved in the $\mathrm{CDCl}_{3}: \mathrm{MeOD}_{\mathbf{O}} \mathrm{D}_{2} \mathrm{O}$ (volume fractions 4:2:1). The spectra used TOCSY mixing times of $70 \mathrm{~ms}$ (a-f) and $120 \mathrm{~ms}$ (g-h). 
Effect on the ${ }^{31} \mathrm{P}$ spectra by varying $\mathrm{pH}$

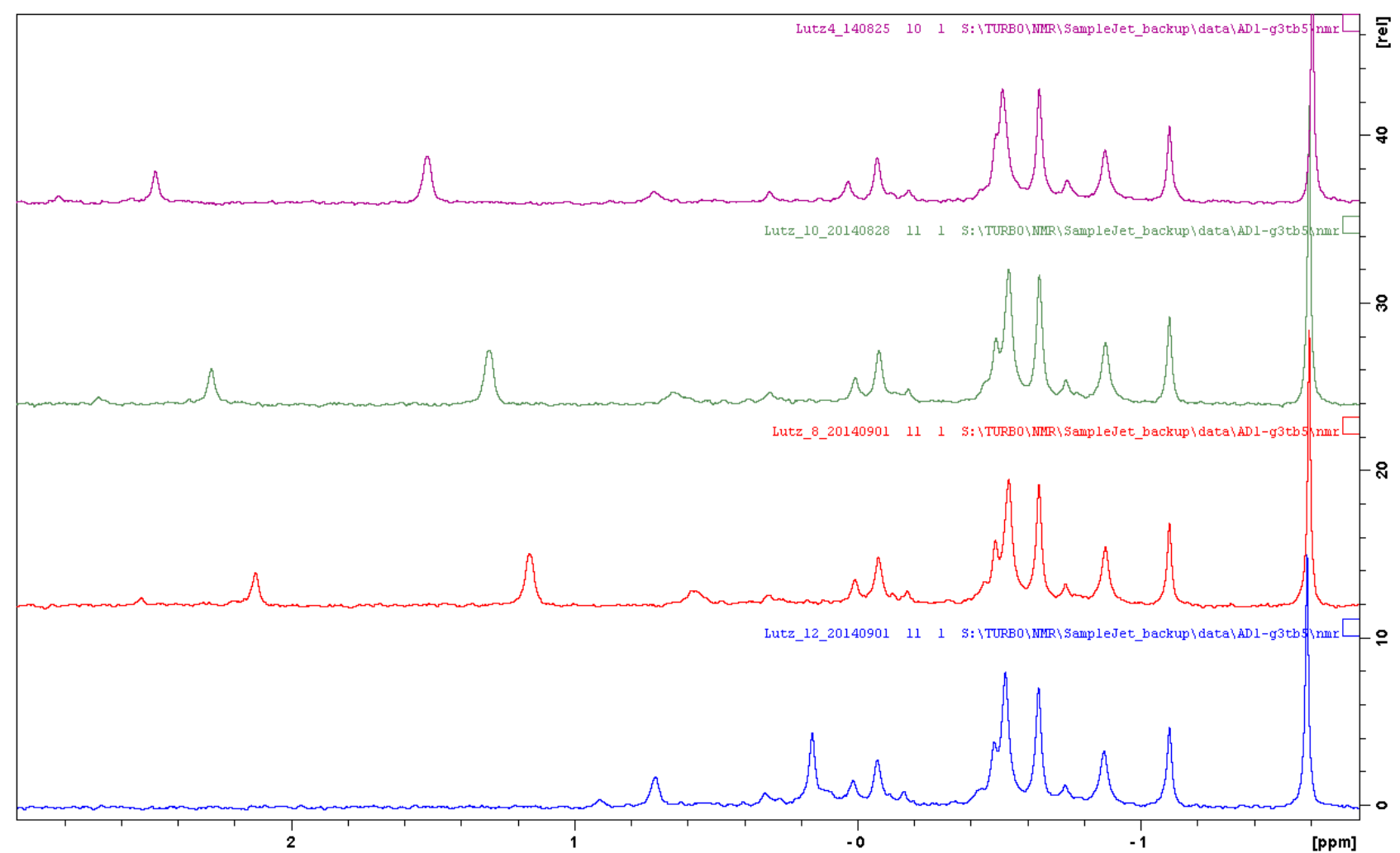

Figure S6. ${ }^{31} \mathrm{P}$ spectra of a soy lecithin sample at a temperature of $278 \mathrm{~K}$ with different $\mathrm{pH}$ values. $\mathrm{Blue}: \mathrm{pH}=5.96 . \mathrm{Red}: \mathrm{pH}=$ 7.78. Green: $\mathrm{pH}=10.80$. Purple: $\mathrm{pH}=11.86$.

\section{Database tables}

The database tables containing the typical chemical shift ranges and relative peak intensities for different mixing times are shown in Table S2 below. 
Table S2. Phospholipid entries in the database for automatic assignment with mixing times of $70 \mathrm{~ms}$ and $120 \mathrm{~ms}^{\mathrm{a}}$.

\begin{tabular}{|c|c|c|c|c|c|c|c|c|c|c|c|c|c|c|c|c|c|c|}
\hline \multirow[t]{2}{*}{ Label } & \multirow{2}{*}{$\begin{array}{c}\text { Mix. Time } \\
{[\mathrm{ms}]}\end{array}$} & \multirow{2}{*}{$\begin{array}{l}v_{P, j}^{\mathrm{db}} \\
{[p p m]}\end{array}$} & \multicolumn{8}{|c|}{$v_{\mathrm{H}, j, i}^{\mathrm{db}}[\mathrm{ppm}]$} & \multicolumn{8}{|c|}{$I_{j, i}^{\mathrm{db}}[\%]$} \\
\hline & & & 1 & 2 & 3 & 4 & 5 & 6 & 7 & 8 & 1 & 2 & 3 & 4 & 5 & 6 & 7 & 8 \\
\hline \multirow[t]{2}{*}{ TIBP } & 70 & -0.36 & 0.98 & 3.82 & 1.98 & & & & & & 100 & 36 & 12 & & & & & \\
\hline & 120 & -0.36 & 0.98 & 3.82 & 1.98 & & & & & & 100 & 6 & 5 & & & & & \\
\hline \multirow[t]{2}{*}{ PC } & 70 & 0.14 & 3.63 & 3.98 & 4.26 & 4.16 & 4.42 & 5.23 & & & 100 & 64 & 55 & 13 & 13 & 8 & & \\
\hline & 120 & 0.14 & 3.63 & 3.98 & 4.26 & 4.16 & 4.42 & 5.23 & & & 100 & 25 & 100 & 30 & - & 6 & & \\
\hline \multirow[t]{2}{*}{ PI } & 70 & 0.36 & 4.04 & 4.19 & 3.73 & 3.46 & 3.27 & 3.88 & 5.25 & 4.44 & 100 & 40 & 39 & 38 & 33 & 31 & 28 & 28 \\
\hline & 120 & 0.36 & 4.04 & 4.19 & 3.73 & 3.46 & 3.27 & 3.88 & 5.25 & 4.44 & 38 & 100 & 39 & 48 & 32 & - & - & 76 \\
\hline \multirow[t]{2}{*}{ LPC1 } & 70 & 0.50 & 3.63 & 4.00 & 4.26 & 3.72 & & & & & 100 & 56 & 54 & 43 & & & & \\
\hline & 120 & 0.50 & 3.63 & 4.00 & 4.26 & 3.72 & & & & & 100 & - & 100 & 100 & & & & \\
\hline \multirow[t]{2}{*}{ LPC2 } & 70 & 0.59 & 3.63 & 4.27 & 3.86 & 3.92 & 4.13 & 4.01 & & & 100 & 55 & 35 & 34 & 28 & 14 & & \\
\hline & 120 & 0.59 & 3.63 & 4.27 & 3.86 & 3.92 & 4.13 & 4.01 & & & 100 & 100 & 15 & 15 & 50 & 18 & & \\
\hline GPC & 70 & 0.70 & 3.63 & 3.84 & 4.27 & 3.92 & & & & & 100 & 54 & 53 & 49 & & & & \\
\hline \multirow[t]{2}{*}{ PE } & 70 & 0.75 & 3.18 & 4.05 & 3.98 & 4.17 & 4.42 & 5.22 & & & 100 & 56 & 44 & 12 & 12 & 9 & & \\
\hline & 120 & 0.75 & 3.18 & 4.05 & 3.98 & 4.17 & 4.42 & 5.22 & & & 90 & 100 & 31 & 34 & 33 & 6 & & \\
\hline \multirow[t]{2}{*}{ NAP } & 70 & 1.05 & 3.88 & 3.96 & 3.42 & 4.17 & 4.41 & & & & 100 & 84 & 80 & 16 & 15 & & & \\
\hline & 120 & 1.05 & 3.88 & 3.96 & 3.42 & 4.17 & 4.41 & & & & 100 & 37 & 67 & 40 & 41 & & & \\
\hline \multirow[t]{2}{*}{ LPE } & 70 & 1.16 & 3.19 & 4.07 & 3.92 & 3.86 & & & & & 100 & 82 & 38 & 36 & & & & \\
\hline & 120 & 1.16 & 3.19 & 4.07 & 3.92 & 3.81 & 4.11 & & & & 78 & 100 & 19 & 21 & 76 & & & \\
\hline GPE & 70 & 1.25 & 3.20 & 4.07 & 3.84 & 3.60 & 3.92 & & & & 100 & 78 & 70 & 56 & 47 & & & \\
\hline NAL & 70 & 1.54 & 3.89 & 3.41 & 4.12 & & & & & & 100 & 63 & 37 & & & & & \\
\hline \multirow[t]{2}{*}{ PA } & 70 & 2.69 & 3.92 & 4.19 & 4.44 & 5.24 & & & & & 100 & 15 & 15 & 15 & & & & \\
\hline & 120 & 2.69 & 3.86 & 4.19 & 4.44 & 5.24 & 3.82 & & & & 70 & 87 & 100 & 21 & 75 & & & \\
\hline LPA & 70 & 3.68 & 3.85 & 4.12 & 4.00 & & & & & & 100 & 77 & 42 & & & & & \\
\hline GPA & 70 & 4.03 & 3.85 & 3.82 & 3.58 & & & & & & 100 & 100 & 59 & & & & & \\
\hline
\end{tabular}

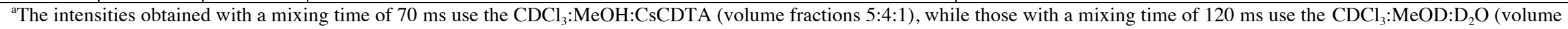
fractions 4:2:1) solvent system. 


\section{Pulse sequence}

For the $2 \mathrm{D}{ }^{1} \mathrm{H}_{-}{ }^{31} \mathrm{P}$ heteronuclear TOCSY experiments, we employed the Bruker pulse program na_hpdi with modifications to a setup where all amplifier references to $\mathrm{f} 3$ has been changed to f2.

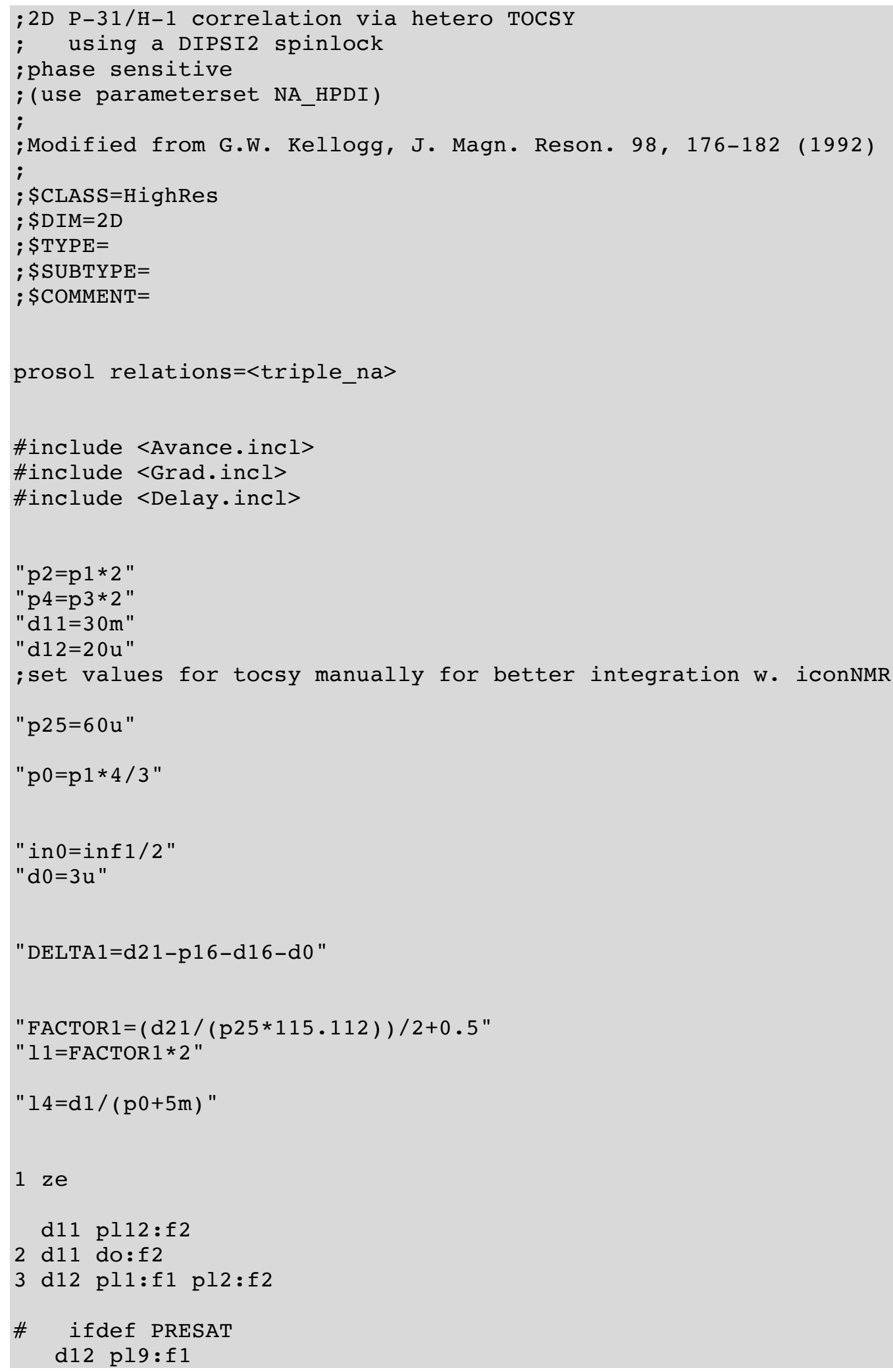




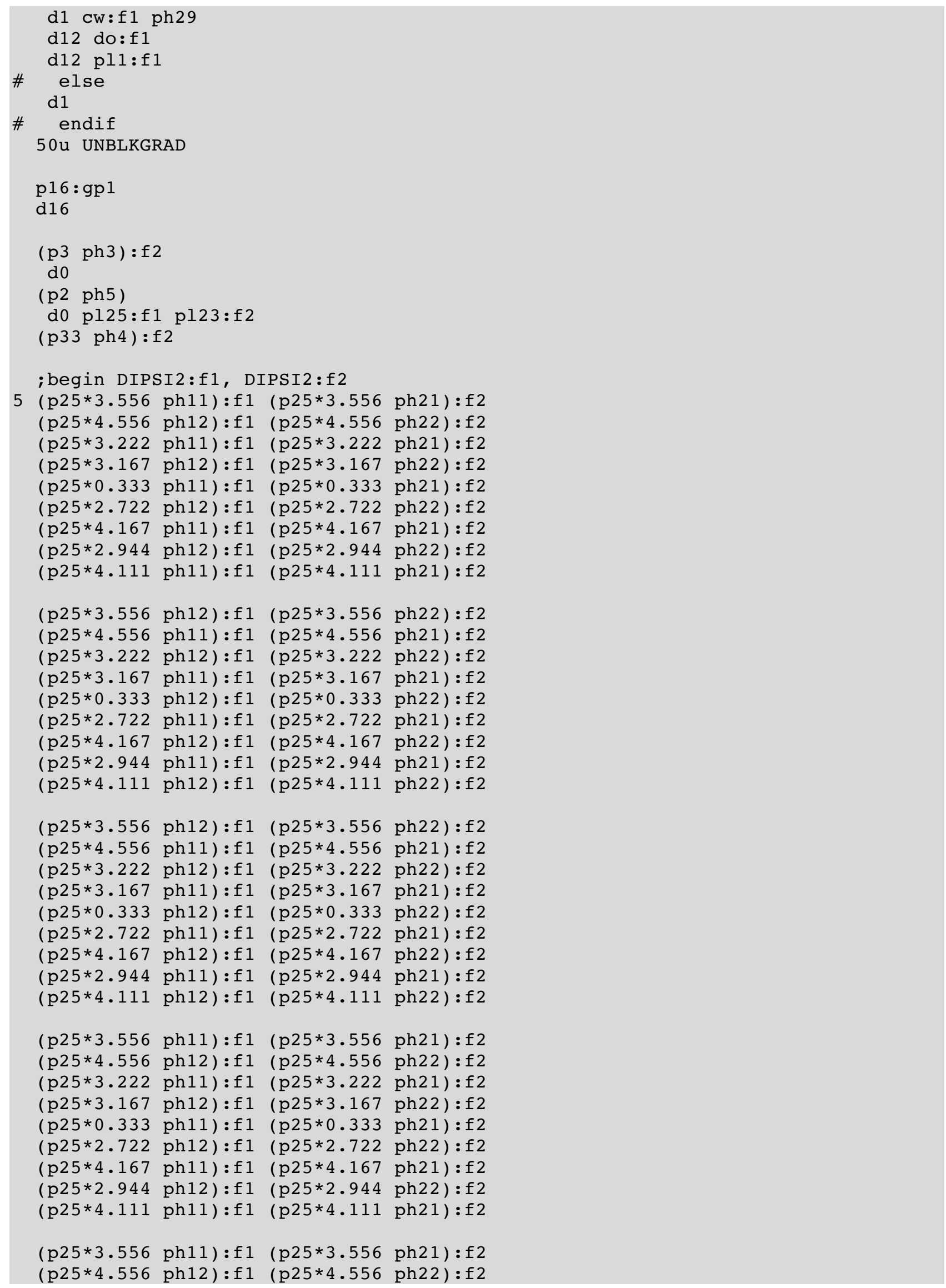




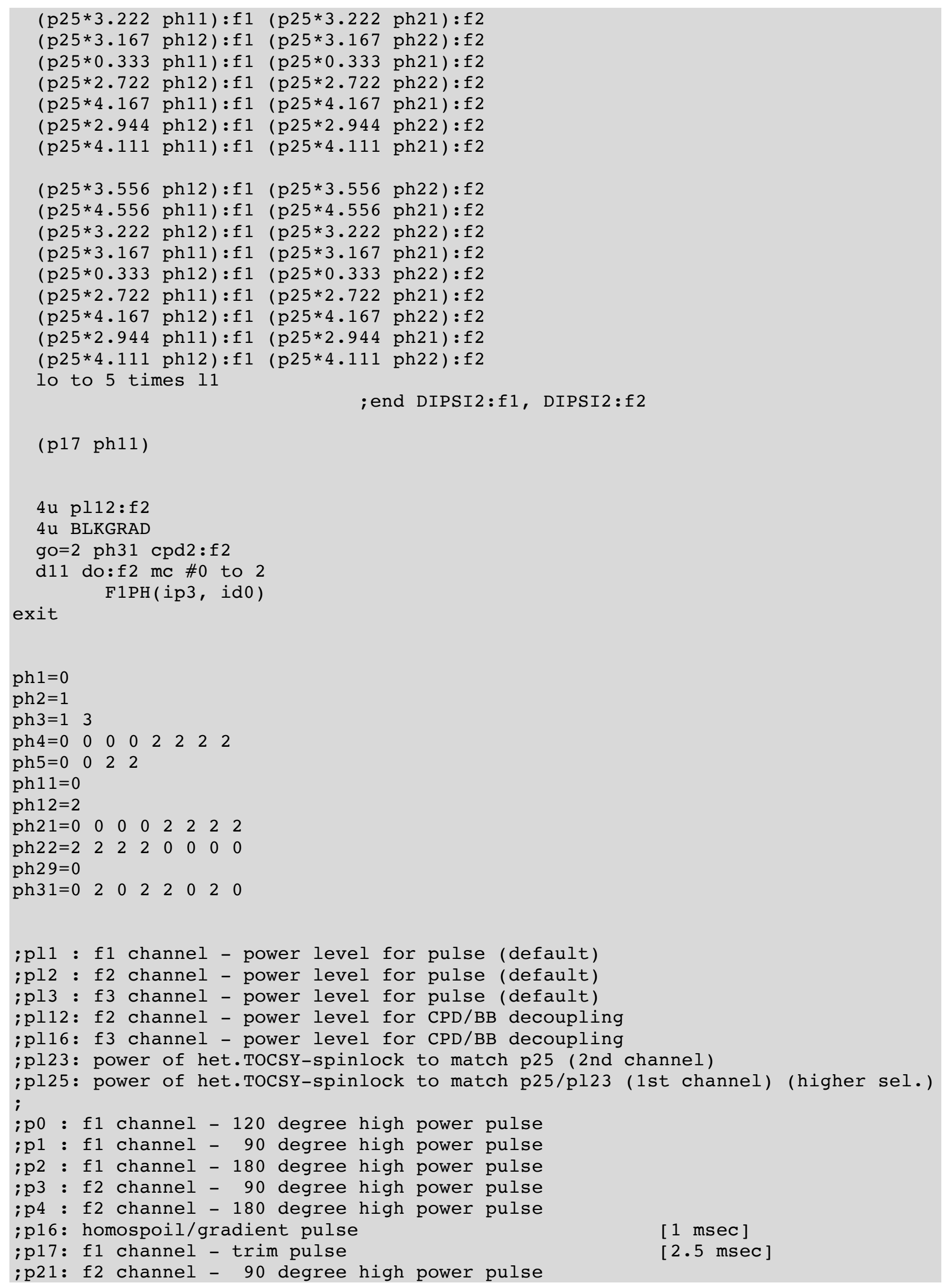




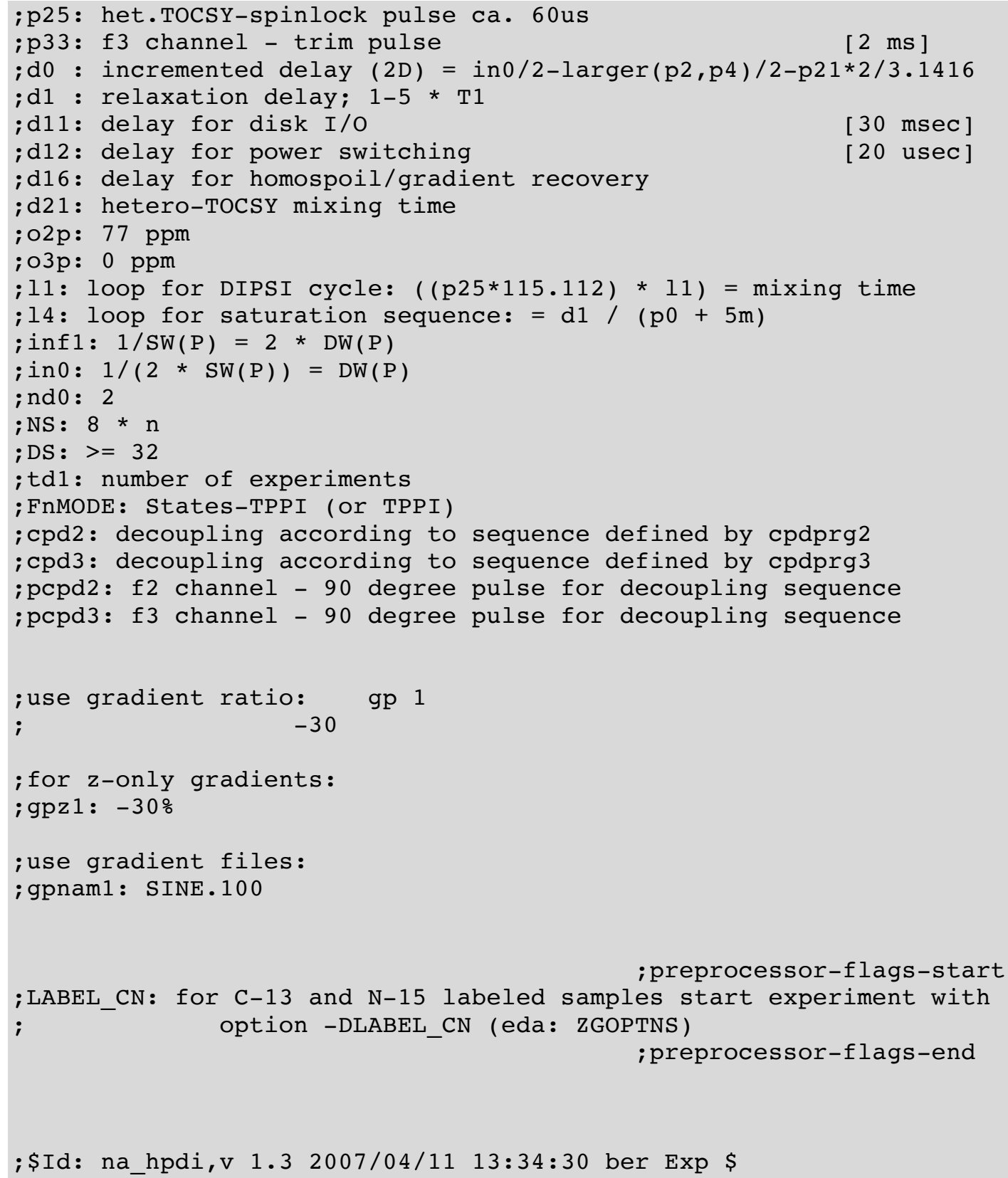

